\title{
APLICAÇÃo de POTÁSSIO NO ESTADO NUTRICIONAL E NA PRODUÇÃo DE MATÉRIA SECA DE MUDAS DE MARACUJAZEIRO-AMARELO' ${ }^{1}$
}

\author{
RENATO DE MELLO PRADO ${ }^{2}$, LUIZ FERNANDO BRAGHIROLLI ${ }^{3}$, WILLIAM NATALE ${ }^{2,5}$, MÁRCIO CLEBER DE \\ MEDEIROS CORRÊA ${ }^{4}$, ELIOZÉAS VICENTE DE ALMEIDA ${ }^{4}$
}

\begin{abstract}
RESUMO - O subsolo, normalmente utilizado para a produção de mudas de espécies frutíferas, apresenta baixa concentração de potássio e, assim, existe grande probabilidade de resposta à aplicação deste nutriente. Desse modo, objetivou-se avaliar a aplicação de potássio ao substrato de produção de mudas de maracujazeiro-amarelo (Passiflora edulis) e os seus efeitos no desenvolvimento, na produção de matéria seca e no estado nutricional das plantas. O delineamento experimental foi o de blocos ao acaso, com cinco tratamentos e quatro repetições. As doses de potássio (cloreto de potássio) foram: 0; 75; 150; 225 e $300 \mathrm{mg} \mathrm{de} \mathrm{K} \mathrm{dm}^{-3}$. As mudas receberam doses de N, P, B e Zn de 300; 450; 0,5 e 5 mg dm ${ }^{-3}$, respectivamente. O experimento foi conduzido em casa de vegetação, em vasos com $2 \mathrm{dm}^{3}$ de solo (Latossolo Vermelho distrófico), durante 60 dias. A aplicação de potássio afetou de forma quadrática o desenvolvimento e a nutrição de mudas do maracujazeiro. A maior produção de massa seca das plantas ocorreu na faixa entre $200-220 \mathrm{mg}$ de $\mathrm{K} \mathrm{dm}^{-3}$, e concentração de $3 \mathrm{mmol}_{\mathrm{c}}$ de $\mathrm{K} \mathrm{dm}^{-3}$ no solo.
\end{abstract}

Termos para indexação: Passiflora edulis, nutrição, adubação.

\section{POTASSIUM APPLICATION ON THE NUTRICIONAL STATUS AND DRY MATTER PRODUCTION OF PASSION FRUIT CUTTINGS}

\begin{abstract}
The subsoil, normally used for passion fruit cuttings production, presents low potassium concentration and, thus, great probability of response to the application of this nutrient. Thus, it was evaluated the application of potassium to the substratum of production, to follow the effects in the development, the production of dry matter and the nutricional status of the plants. The experimental design used was randomized blocks with 5 treatments and 4 replications. The doses of potassium were: $0 ; 75 ; 150 ; 225$ and $300 \mathrm{mg} \mathrm{of} \mathrm{K} \mathrm{dm}^{-3}$. All the plants received constant doses of N, P, B and $\mathrm{Zn}$ of 300; 450; 0.5 and $5 \mathrm{mg} \mathrm{dm}^{-3}$ respectively. The experiment was lead in pot with $2 \mathrm{dm}^{3}$ of substratum of a Red Latosol (Oxisol), during 60 days. The potassium application affected the quadratic form of the growth and the nutrition of the passion fruit. The biggest production of dry matter of the plants was associated with the dose near to $200-220 \mathrm{mg}$ of $\mathrm{K} \mathrm{dm}^{-3}$, and $3 \mathrm{mmol}_{\mathrm{c}}$ of $\mathrm{K} \mathrm{dm}^{-3}$ in the soil.
\end{abstract}

Index terms: Passiflora edulis, nutrition, fertilization.

\section{INTRODUÇÃO}

A importância do potássio para as plantas é devido às suas diversas funções, participando de processos osmóticos, da síntese de proteínas, da abertura e fechamento de estômatos, da permeabilidade da membrana, do controle do $\mathrm{pH}$ e da ativação de cerca de 60 sistemas enzimáticos (Malavolta et al., 1997).

$\mathrm{Na}$ literatura, a descrição geral de deficiência de potássio em maracujazeiro é dada pelo atraso na floração e diminuição no tamanho dos frutos. Ocorre, ainda, redução significativa da área verde foliar, afetando a fotossíntese e, por conseguinte, o teor de sólidos solúveis dos frutos (Ruggiero, 1996).

A maioria da experimentação com potássio foi realizada na fase de produção da cultura, sendo poucos os ensaios com potássio em mudas de maracujazeiro. Os estudos existentes apresentam contradições quanto à resposta do maracujazeiro à aplicação de potássio, havendo ausência de resposta na produção de frutos (Sanzonowicz et al., 2000; Rangel et al., 2002) e resposta na produção de frutos (Carvalho et al., 1999) e no teor de sólidos solúveis e rendimento de suco (Martins, 1998). Outros estudos demonstram que a exigência do maracujazeiro em potássio supera o nitrogênio. Neste sentido, Carvalho et al. (2001) verificaram em maracujazeiro-amarelo que a maior produção de frutos e de suco foi observada quando a relação foliar $\mathrm{N}: \mathrm{K}$ era igual a 1:2,2 e 1:2,8, respectivamente. São José (1994) indica adubação anual para essa fruteira em que a relação N:K esteja em torno de 1:2,5. Santos et al. (2001) estudaram as relações $\mathrm{N}: \mathrm{K}$ em maracujazeiro e observaram maior desenvolvimento vegetativo quando se aplicaram 3 vezes mais potássio que nitrogênio. Entretanto, os autores acrescentam que altas doses de K podem provocar toxidez de $\mathrm{Cl}$ nas plantas, quando se usa cloreto de potássio. Estudos em condições de campo, com maracujazeiro-amarelo irrigado, indicaram que a aplicação de potássio influenciou positivamente no peso e no diâmetro médio do fruto e, negativamente, na produtividade (Borges et al., 2003) e positivamente na produtividade (Souza et al., 2003).

Diante do exposto, objetivou-se avaliar os efeitos da aplicação de potássio ao substrato de produção de mudas de maracujazeiro, no desenvolvimento, no estado nutricional e na produção de matéria seca das plantas.

\section{MATERIAL E MÉTODOS}

O trabalho foi conduzido em condições de casa de vegetação, na FCAV/Unesp, Jaboticabal-SP. Como substrato, utilizou-se o subsolo de um Latossolo Vermelho distrófico (camada 3-4 m). Realizaram-se análises químicas do substrato, antes da calagem e após 30 dias de incubação do solo com o calcário, por ocasião da semeadura (Tabela 1). A aplicação do corretivo de acidez objetivou elevar o $\mathrm{V}$ a $80 \%$, conforme recomendação de Piza Júnior et al. (1996). Para isso, foi utilizado o calcário calcinado tipo $\mathrm{D}$, com as seguintes características: $\mathrm{CaO}=420 \mathrm{~g} \mathrm{~kg}^{-1} ; \mathrm{MgO}=250 \mathrm{~g} \mathrm{~kg}^{-1}$; $\mathrm{PN}=137 \% ; \mathrm{RE}=96 \%, \mathrm{e} \mathrm{PRNT}=131 \%$. A dose de calcário calculada $(0,9 \mathrm{t}$ ha $^{-1}$ ou $0,880 \mathrm{~g}$ por vaso de $2 \mathrm{dm}^{3}$ ) foi homogeneamente aplicada ao substrato, 30 dias antes da semeadura e da aplicação dos tratamentos, de modo que o corretivo tivesse tempo suficiente para neutralizar a acidez do solo.

O delineamento experimental adotado foi em blocos casualizados, com cinco tratamentos e quatro repetições, totalizando 20 unidades experimentais, composta de vaso de $2 \mathrm{dm}^{-3}$. Os tratamentos foram doses crescentes de potássio, na forma de cloreto de potássio $\left(60 \%\right.$ de $\left.\mathrm{K}_{2} \mathrm{O}\right)$, considerando-se como parâmetro a dose média de $150 \mathrm{mg} \mathrm{de} \mathrm{K} \mathrm{dm}^{-3}$, indicada como adequada para experimentos em condições de vasos, segundo recomendação geral de Malavolta (1981). As doses foram calculadas como se segue: $D_{0}=$ zero $; D_{1}=75 ; D_{2}=150 ; D_{3}=225$, e $D_{4}=300$ $\mathrm{mg} \mathrm{de} \mathrm{K} \mathrm{dm}^{-3}$ de substrato. Estas doses corresponderam a: 0; 0,30; 0,60;

\footnotetext{
${ }^{1}$ (Trabalho 019/2004). Recebido: 17/02/2004. Aceito para publicação: 21/07/2004.

${ }_{2}^{2}$ Prof. Depto de Solos e Adubos, Faculdade de Ciências Agrárias e Veterinárias, Unesp (Via de Acesso Prof. Paulo Donato Castellane, s/n. 14870-000, Jaboticabal-SP). rmprado@fcav.unesp.br

${ }^{3}$ Graduando, Depto de Solos e Adubos, Faculdade de Ciências Agrárias e Veterinárias, Unesp.

${ }^{4}$ Pós-granduando, Depto. de Solos e Adubos, Faculdade de Ciências Agrárias e Veterinárias, Unesp.

${ }^{5}$ Bolsista do CNPq.
} 
TABELA 1- Propriedades químicas do substrato ${ }^{(*)}$ de um Latossolo Vermelho distrófico, utilizado na produção de mudas de maracujazeiro

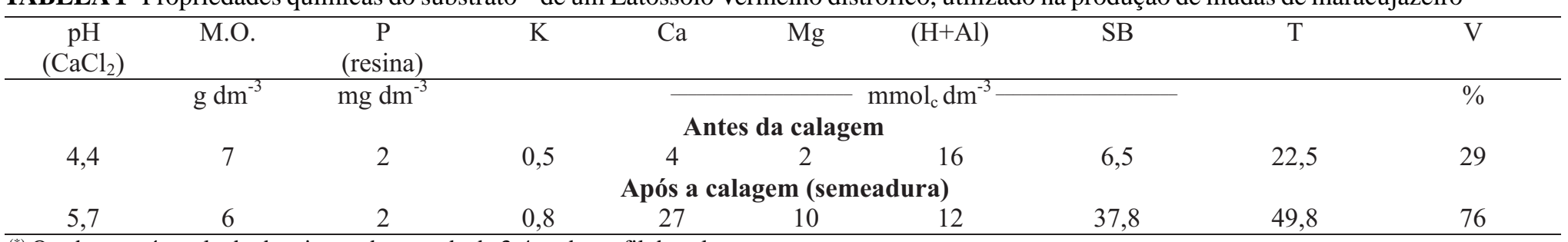

(*) O substrato é resultado da mistura da camada de 3-4 $\mathrm{m}$ do perfil do solo.

0,90 e $1,80 \mathrm{~g}$ de cloreto de potássio por vaso, respectivamente.

Ainda por ocasião da semeadura, cada unidade experimental recebeu doses de nivelamento para $\mathrm{P}\left(450 \mathrm{mg} \mathrm{dm}^{-3}\right)$, conforme indicação de Machado (1998), N (300 mg dm $\left.{ }^{-3}\right), \mathrm{B}\left(0,5 \mathrm{mg} \mathrm{dm}^{-3}\right)$, de acordo com a recomendação geral de Malavolta (1981), e de $\mathrm{Zn}\left(5 \mathrm{mg} \mathrm{dm}^{-3}\right)$ (Lopes, 2000), na forma de superfosfato triplo (44\% de $\left.\mathrm{P}_{2} \mathrm{O}_{5}\right)$, uréia $(45 \%$ de $\mathrm{N})$, ácido bórico (17\% de B) e sulfato de zinco (22\% de Zn), respectivamente. O N foi parcelado em quatro vezes, aos 15; 30; 40 e 50 dias após a semeadura, e o K em três vezes, aos 15; 30 e 40 dias. O P, o B e o $\mathrm{Zn}$ foram adicionados em dose total na semeadura.

Empregaram-se seis sementes do maracujazeiro-amarelo por vaso. Uma semana após a emergência das plântulas, realizou-se o desbaste, deixando-se três mudas por vaso até o final do experimento.

A irrigação foi mantida continuamente durante todo o período experimental, tomando como base a umidade correspondente a $70 \%$ da capacidade de campo do solo.

Aos 60 dias após a semeadura, quando as plantas estavam bem desenvolvidas, foram avaliados os seguintes parâmetros biológicos indicativos do desenvolvimento das plantas: diâmetro do caule, altura, índice de área foliar, massa seca da parte aérea e das raízes a partir da média das 3 plantas de cada vaso. Na mesma ocasião, o estado nutricional das plantas foi avaliado, a partir dos nutrientes absorvidos e acumulados (teor do nutriente x massa seca), na parte aérea e raízes das mudas. As amostras dos tecidos vegetais foram secas em estufa a $65^{\circ} \mathrm{C}$ até atingir peso constante. As determinações dos teores de macro e micronutrientes no tecido vegetal seguiram a metodologia de Bataglia et al. (1983). Amostragens de solo foram realizadas ao final do ensaio, e as determinações analíticas seguiram as recomendações de Raij et al. (2001).

Com base nos resultados obtidos, realizaram-se a análise de variância para os diversos parâmetros estudados e a análise de correlação entre os tratamentos e as determinações no solo e na planta.

\section{RESULTADOSEDISCUSSÃO}

\section{Efeito dos tratamentos no solo}

Após 30 dias da aplicação do calcário ao substrato, realizou-se análise química do solo, observando-se neutralização da acidez e elevação da saturação por bases a $76 \%$. A concentração de $\mathrm{K}$ passou de 0,5 para 0,8 mmol $\mathrm{dm}^{-3}$ (Tabela 1), porém ambos os valores no solo são considerados baixos, segundo Raij et al. (1996). Para avaliar a probabilidade de resposta das plantas à adubação potássica, é utilizada, além da concentração absoluta de $\mathrm{K}$ no solo, a sua relação com as bases $\mathrm{Ca}$ e $\mathrm{Mg}$. Neste sentido, Castro \& Meneghelli (1989) indicam o índice 0,20 para a relação K/ $(\mathrm{Ca}+\mathrm{Mg})^{1 / 2}$ como o limite, a partir do qual as adubações potássicas devem apresentar respostas progressivamente menores e, portanto, antieconômicas. Assim, para o presente experimento, a citada relação foi de 0,16 e, por conseguinte, com probabilidade de resposta da planta à fertilização potássica.

Aos 60 dias após a semeadura, observou-se que a aplicação de potássio elevou de forma linear a concentração de potássio no solo (Figura 1). Verifica-se que, para cada $1 \mathrm{mg} \mathrm{dm}^{-3}$ de potássio aplicado, houve recuperação de $0,0144 \mathrm{mmol}_{\mathrm{cm}} \mathrm{dm}^{-3}$ (ou $0,56 \mathrm{mg} \mathrm{dm}^{-3}$ ), sendo, pois, a recuperação do elemento, de $56 \%$. Resultados semelhantes foram obtidos por Teixeira et al. (2001) em solo cultivado com bananeira em condições de campo, recuperando cerca de 50\% do K aplicado.

Efeito dos tratamentos no desenvolvimento e na produção de matéria seca Houve efeito significativo das doses de potássio sobre o diâmetro

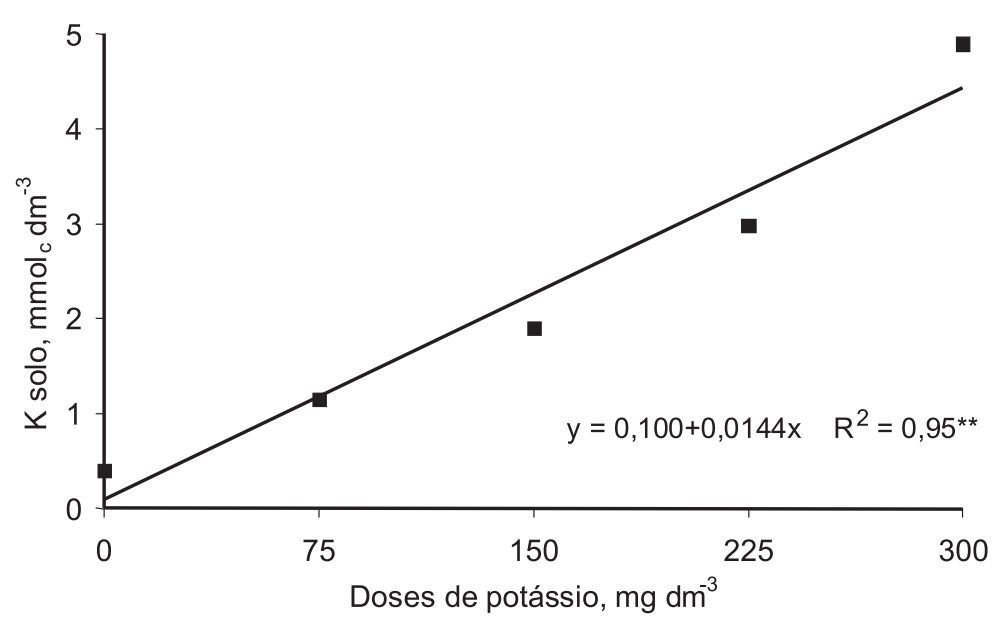

FIGURA 1- Efeito das doses de potássio na concentração de K no substrato do Latossolo Vermelho distrófico.

do caule, a altura e a área foliar das mudas de maracujazeiro (Figura 2a, b). Pelo estudo das regressões, verificou-se que as plantas atingiram o máximo

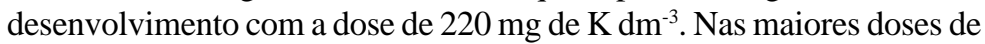
potássio, as plantas apresentaram decréscimo no desenvolvimento, não exibindo, porém, sintomatologia de toxidez, que pode ocorrer tanto devido ao potássio como ao cloro. Segundo Malavolta et al. (1997), os sintomas de excesso de potássio podem caracterizar-se por deficiência de magnésio induzida, enquanto o excesso de cloro provoca necrose das margens, amarelecimento prematuro e abscisão das folhas.

A massa seca da parte aérea e das raízes das mudas de maracujazeiro foi afetada de forma quadrática pelas doses de K (Figura 3), como conseqüência dos incrementos promovidos nas características de desenvolvimento (diâmetro do caule, altura e área foliar das plantas). Efeitos positivos do $\mathrm{K}$ foram observados em algumas espécies, inclusive do maracujazeiro, tanto no crescimento da parte aérea como do sistema radicular, dada a conhecida função deste nutriente no metabolismo das plantas (Malavolta et al., 1997).

Da mesma forma que ocorreu com o diâmetro do caule, a área foliar e a altura das mudas, a maior produção de matéria seca da parte aérea e das raízes esteve associada à dose de cerca de $200 \mathrm{mg} \mathrm{de} \mathrm{K} \mathrm{dm}^{-3}$, conforme indica a Figura 3. A relação entre a concentração de K no solo e a produção de matéria seca da parte aérea $\left(y=0,45+1,272 x-0,2076 x^{2}, R^{2}=0,99 * *\right)$ e das raízes $\left(y=0,14+0,207 x-0,0357 x^{2}, R^{2}=0,97 * *\right)$ indica que a concentração de $3 \mathrm{mmol}_{\mathrm{c}} \mathrm{dm}^{-3}$ de potássio no solo esteve associada à maior produção de matéria seca, tanto da parte aérea como das raízes.

$\mathrm{Na}$ Figura 3, pode ser observado, nas doses de 225 e $300 \mathrm{mg}$ de $\mathrm{K} \mathrm{dm}^{-3}$, que houve redução no crescimento e na produção de matéria seca das plantas, o que, segundo Maynard et al. (1976), pode ocorrer devido aos efeitos depressivos causados, pelo menos em parte, pelo cloreto, como, por exemplo, o antagonismo do $\mathrm{Cl}^{-}$em relação ao nitrato, e não apenas pelo potássio. Como na maior dose de $\mathrm{K}$ a concentração deste elemento atingiu $5 \mathrm{mmol} \mathrm{dm}^{-3}$ (Figura 1), isso pode ter provocado efeito salino nas mudas do maracujazeiro. Neste sentido, Silva et al. (2001) verificaram, em pimentão, que o potássio aplicado como $\mathrm{KCl}$ prejudicou o crescimento das raízes, provavelmente associado à sua alta saturação no solo e a possíveis efeitos salinos, correspondendo à concentração entre 5 e $7 \mathrm{mmol}_{\mathrm{c}}$ de $\mathrm{K} \mathrm{dm}^{-3}$. Em eucalipto, Silva et al. (2002) observaram, também, incremento quadrático na produção de matéria (parte aérea e raiz) das mudas, em função de doses de $\mathrm{K}\left(0\right.$ até $\left.150 \mathrm{mg} \mathrm{dm}^{-3}\right)$, especialmente em Latossolo Vermelho-Amarelo franco-arenoso $\left(\mathrm{K}=35 \mathrm{mg} \mathrm{dm}^{-3} \mathrm{e}\right.$ densidade 

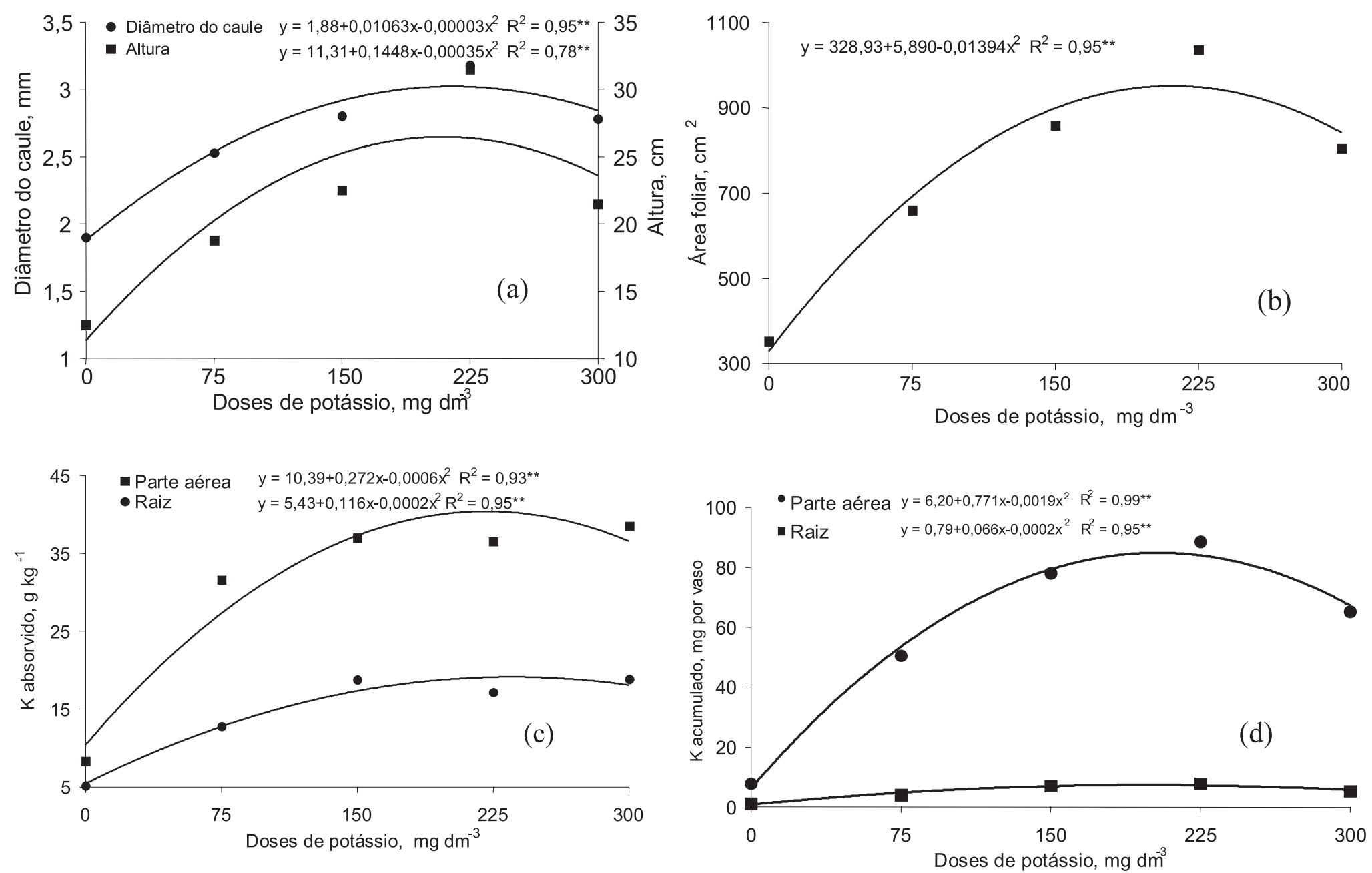

FIGURA 2- Efeito da aplicação de potássio em substrato de Latossolo Vermelho distrófico sobre o diâmetro do caule e a altura (a), a área foliar (b) e na absorção (c) e acúmulo de potássio (d) das mudas de maracujazeiro, aos 60 dias após a semeadura.

$1,5 \mathrm{~g} \mathrm{~cm}^{-3}$ ). Notaram, ainda, que, na maior dose de $\mathrm{K}$, houve queda em alguns parâmetros de crescimento radicular (superfície radicular e diâmetro radicular). Santos et al. (2001) verificaram que altas doses de K (na forma de $\mathrm{KCl}$ ) reduziram o crescimento das mudas de maracujazeiro, provocando toxidez de cloro.

\section{Efeitos dos tratamentos no estado nutricional}

Através dos resultados, observa-se que as características avaliadas de crescimento e produção de matéria seca aumentaram, até certo ponto, com o incremento das doses de K. Procurou-se, pois, estabelecer relações entre o potássio aplicado ao solo e a absorção e o acúmulo de macronutrientes pelas plantas, com o intuito de obter

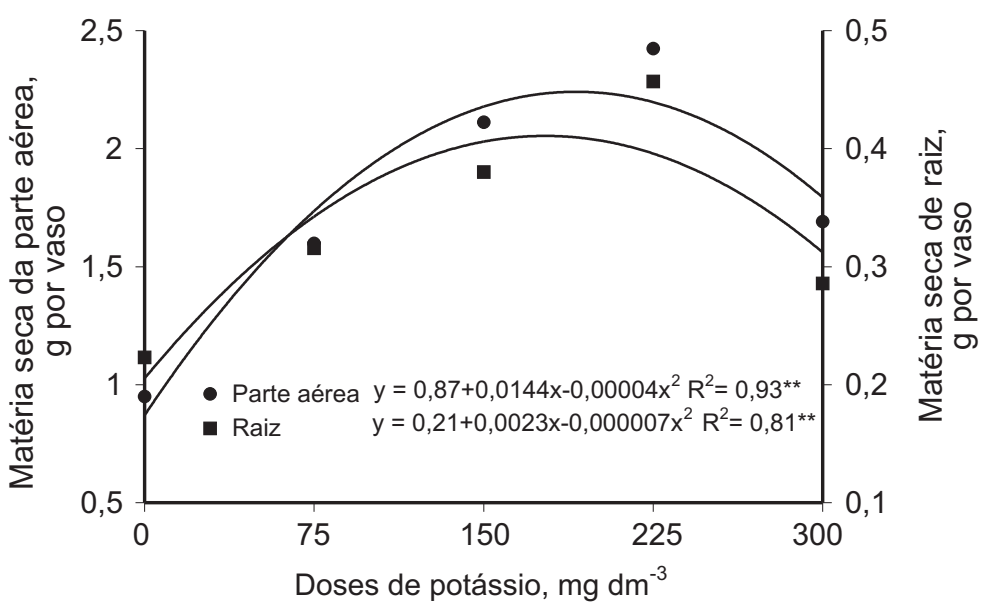

FIGURA 3- Efeito da aplicação de potássio em substrato de Latossolo Vermelho distrófico sobre a produção de matéria seca da parte aérea e das raízes das mudas de maracujazeiro, aos 60 dias após a semeadura. informações que fundamentem os efeitos da adubação para a produção de mudas de maracujazeiro.

A absorção e o acúmulo de potássio na matéria seca da parte aérea e das raízes aumentaram progressivamente com a elevação das doses de K (Figura 2c, d). Os teores de potássio considerados adequados em folhas de maracujazeiro adulto situam-se entre 20-30 segundo Menzel et al. (1993), e entre 35-45 mg de $\mathrm{K} \mathrm{kg}^{-1}$ de acordo com Malavolta (1989). No entanto, no presente estudo, os teores alcançaram valores superiores na parte aérea das mudas $\left(38,5 \mathrm{~g} \mathrm{~kg}^{-1}\right)$ (Figura 3c), com relação a Menzel et al. (1993) e dentro da faixa adequada, conforme Malavolta (1989). Deve-se ressaltar, porém, que os tecidos vegetais amostrados são distintos, sendo, para os autores citados, que a amostragem do tecido vegetal é um par de folhas específico de plantas adultas, enquanto, no presente estudo, coletouse toda a parte aérea das mudas.

O acúmulo de potássio na planta (parte aérea e raízes) descreveu um comportamento quadrático (Figura 2d), indicando que o aumento de $\mathrm{K}$ no solo provocou decréscimo na acumulação do elemento na planta.

$\mathrm{O}$ acúmulo dos demais macronutrientes na parte aérea e nas raízes das mudas de maracujazeiro foi significativamente influenciado pelas doses de $\mathrm{K}$ aplicado, exceto o $\mathrm{N}$ nas raízes (Figura 4). Assim, o incremento do potássio elevou o acúmulo de $\mathrm{N}, \mathrm{P}$ e $\mathrm{S}$ na parte aérea e de $\mathrm{P}$ e $\mathrm{S}$ nas raízes. Carvalho et al. (2001) não observaram incrementos nos teores foliares de $\mathrm{Pe} \mathrm{S}$ em maracujazeiro-amarelo irrigado, com aplicação de potássio. De forma geral, observa-se, inicialmente, um acréscimo, seguido de uma redução, no acúmulo dos macronutrientes nas plantas em função da elevação das doses de K, à semelhança do ocorrido com a produção de matéria seca.

Estudos com aplicação de potássio em maracujazeiro-amarelo irrigado indicaram incremento nos teores de $\mathrm{K}$ e redução nos de $\mathrm{Mg}, \mathrm{Mn}$, Zn e Na nas folhas (Carvalho et al., 2001).

Os efeitos do aumento das doses de K sobre a diminuição no acúmulo de macronutrientes, especialmente do Ca e do $\mathrm{Mg}$, são amplamente relatados na literatura (Mascarenhas et al., 2000; Oliveira et al., 2001). Isso 
se explica pelo fato de o aumento do K disponível no solo intensificar o efeito competitivo sobre a absorção do $\mathrm{Ca}$ e do $\mathrm{Mg}$, uma vez que, durante o processo de absorção radicular, estes nutrientes utilizaram os mesmos sítios carregadores (Malavolta et al., 1997).

Assim, os decréscimos na quantidade de $\mathrm{Ca}$ e $\mathrm{Mg}$ acumulados pelo maracujazeiro ocorreram em função das maiores doses de potássio empregadas e da menor produção de matéria seca (Figura 3). Resultados semelhantes foram obtidos por Bull et al. (1998) na cultura do alho. Estes autores complementam, indicando que o excesso de adubação potássica
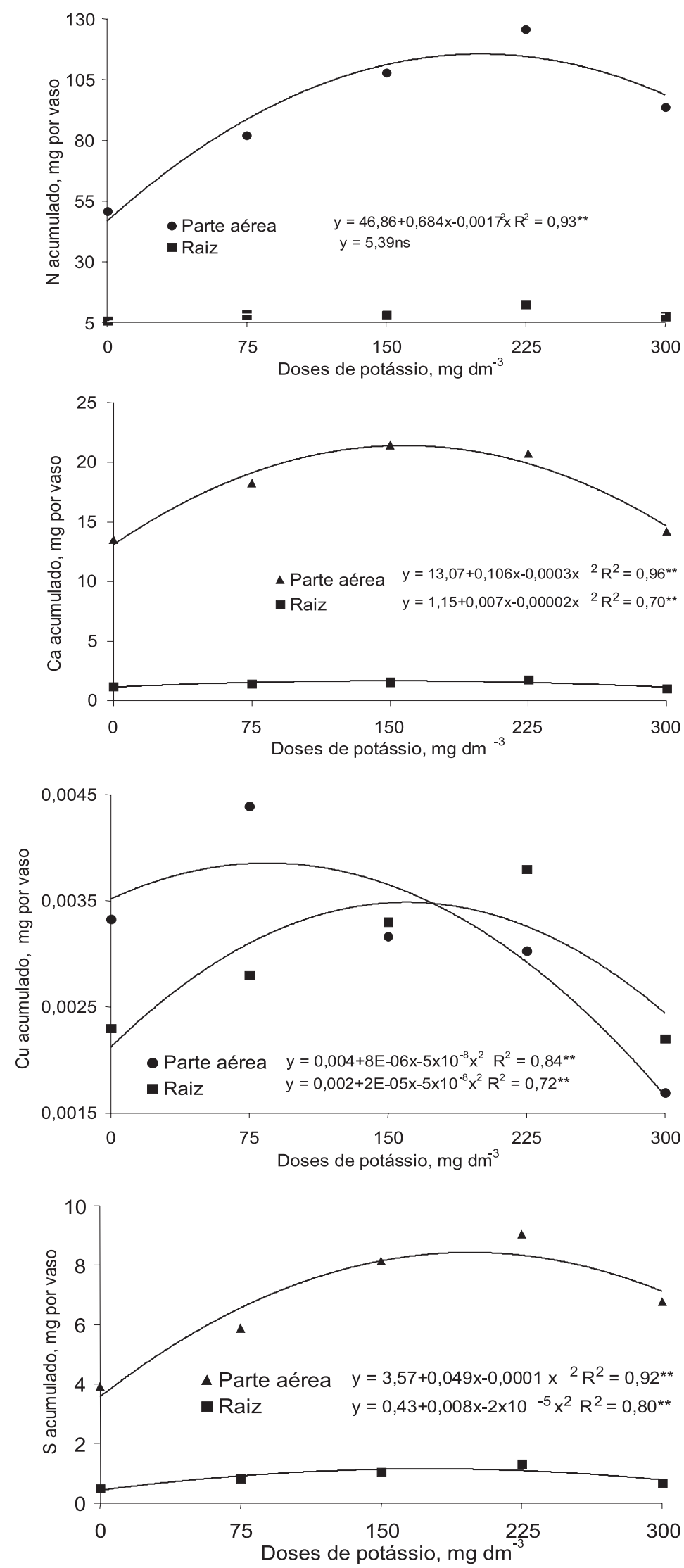

pode inibir mais acentuadamente o crescimento das plantas do que a carência de K, o que pode estar associado ao desbalanço catiônico em relação ao cálcio e magnésio, provocado pela absorção de luxo do potássio. Entre os micronutrientes, Mn, Cu e Zn foram sensíveis à aplicação de K, visto que houve relação quadrática de acúmulo destes elementos na parte aérea e raízes das mudas, em função da aplicação do potássio (Figura 4). Na literatura, tem sido relatado que o excesso de $\mathrm{K}$, na forma de cloreto, pode afetar a absorção destes nutrientes pelas plantas, como o Mn (Silva et al.,1995), o Zn (Schönau,1981) e o Cu (Daliparthy et al., 1994).
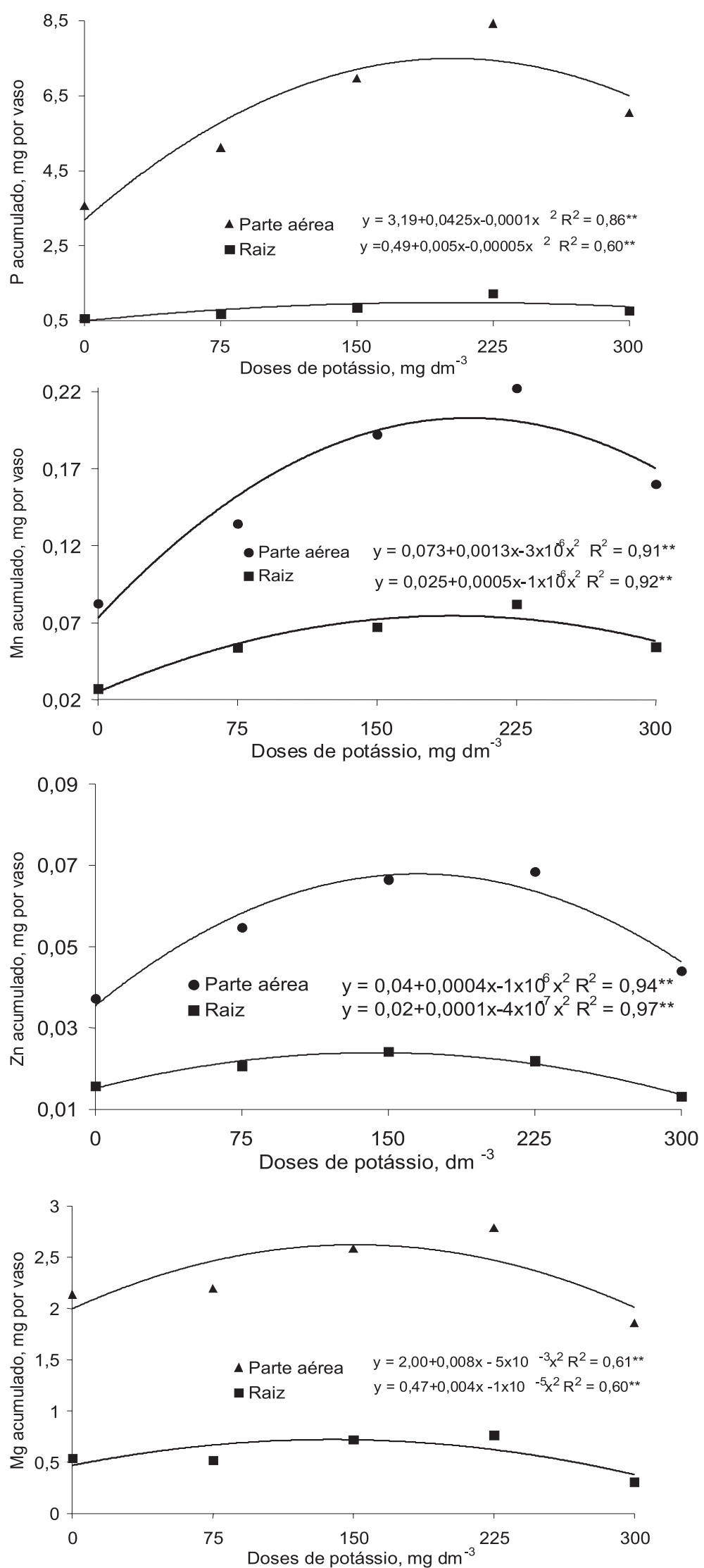

FIGURA 4 - Efeito da aplicação de potássio, em substrato do Latossolo Vermelho distrófico, sobre o acúmulo de N, P, K, Ca, Mg, S, Mn, Cu e Zn na parte aérea e nas raízes de mudas de maracujazeiro, aos 60 dias após a semeadura. 


\section{CONCLUSÕES}

1) A aplicação de potássio afetou de forma quadrática o desenvolvimento e a nutrição do maracujazeiro-amarelo.

2) O maior desenvolvimento e a maior produção de matéria seca das plantas estiveram associadas à dose entre 200-220 mg de K dm 3 e cerca de $3 \mathrm{mmol}_{\mathrm{c}}$ de $\mathrm{K} \mathrm{dm}^{-3}$ de solo e um teor na parte aérea cerca de $39 \mathrm{~g}$ de $\mathrm{K} \mathrm{kg}^{-1}$ e nas raízes de $20 \mathrm{~g}$ de $\mathrm{K} \mathrm{kg}^{-1}$.

\section{REFERÊNCIASBIBLIOGRÁFICAS}

BATAGLIA, O.C.; FURLANI, A.M.C.; TEIXEIRA, J.P.F.; FURLANI, P.R.; GALLO, J.R. Métodos de análise química de plantas. Campinas: Instituto Agronômico, 1983. 48p. (Boletim Técnico, 78).

BORGES, A.L., RODRIGUES, M.G.V.; LIMA, A.A.; ALMEIDA, I.E.; CALDAS, R.C. Produtividade e qualidade de maracujá-amarelo irrigado, adubado com nitrogênio e potássio. Revista Brasileira de Fruticultura, Jaboticabal, v.25, n.2, p.259-262,2003.

BULL, L.T.; VILLAS BOAS, R.L.; NAKAGAWA, J. Variações no balanço catiônico do solo induzidas pela adubação potássica e efeitos na cultura do alho vernalizado. Scientia Agricola, v.55, n.3, p.456-464. 1998.

CARVALHO, A.J.C.; MARTINS, D.P.; MONERAT, P.H.; BERNARDO, S. Produtividade e qualidade do maracujazeiro-amarelo em resposta à adubação potássica sob lâminas de irrigação. Revista Brasileira de Fruticultura, Jaboticabal, v.21, p.333-337,1999.

CARVALHO, A.J.C.; MARTINS, D.P.; MONNERAT, P.H.; BERNARDO, S.; SILVA, J.A. Teores de nutrientes foliares no maracujazeiro-amarelo associados à estação fenológica, adubação potássica e lâminas de irrigação. Revista Brasileira de Fruticultura, Jaboticabal, v.23,p.403408,2001 .

CASTRO, A.F.; MENEGHELLI, N.A. As relações $\mathrm{K}^{+} /\left(\mathrm{Ca}^{++}+\mathrm{Mg}^{++}\right)^{1 / 2} \mathrm{e}$ $\mathrm{K}^{+} /\left(\mathrm{Ca}^{++}+\mathrm{Mg}^{++}\right)$no solo e as respostas à adubação potássica. Pesquisa Agropecuária Brasileira, Brasília, v.24, p.751-760, 1989.

DALIPARTHY, J.; BARKER, A.V.; MONDAL, S.S. Potassium fractions with other nutrients in crops - a review focusing on the tropicals. Journal of Plant Nutritiun, Montecello, v.17,p.1859-1886,1994.

LOPES, P.S.N. Micronutrientes em plantas juvenis de maracujazeirodoce (Passiflora alata Dryand). 2000. 111f. Tese (Doutorado) Universidade Federal de Lavras, Lavras, 2000.

MACHADO, R.A.F. Fósforo e zinco na nutrição e crescimento de mudas de maracujazeiro-amarelo (Passiflora edulis f. flavicarpa Deg.). 93f. Dissertação (Mestrado) - Universidade Federal de Lavras, Lavras, 1998.

MALAVOLTA, E. ABC da adubação. São Paulo: Agronômica Ceres, 1989. 292p.

MALAVOLTA, E. Manual de química agrícola: adubos e adubação. 3.ed. São Paulo: Agronômica Ceres, 1981. 594p.

MALAVOLTA, E.; VITTI, G.C.; OLIVEIRA, S.A. Avaliação do estado nutricional das plantas: princípios e aplicações. Piracicaba: POTAFÓS, 1997.319p.

MARTINS, D.P. Resposta do maracujazeiro-amarelo (Passiflora edulis Sins var. flavicarpa Deg.) a lâminas de irrigação e doses de nitrogênio e potássio. 1998. 84f. Tese (Doutorado) - Universidade Estadual do Norte Fluminense. Campos dos Goyatacazes, 1998.

MASCARENHAS, H.A.A.; TANAKA, R.T.; CARMELLO, Q.A.C. Calcário e potássio para a cultura de soja. Scientia Agricola,v.57, n.3, p.445-449, 2000.

MAYNARD, D.N.; MINOTTI, P.G.; PECK, N.H. Nitrate accumulation in vegetables. Advances in Agronomy, San Diego, v.28,p.71-118,1976.

MENZEL, C.M.; HAYDON, G.F.; DOOGAN, V.J.; SIMPSON, D.R. New standard leaf nutrient concentrations for passion fruit based on sasonal phenology and leaf composition. Journal of Horticultural Science, Ashford, v.68,p.215-229,1993.

OLIVEIRA, F.A.de; CARMELLO, Q.A.C.; MASCARENHAS, H.A.A. Disponibilidade de potássio e suas relações com cálcio e magnésio em soja cultivada em casa de vegetação. Scientia Agricola,v.58, n.2, p.329-335, 2001.

PIZAJÚNIOR, C.T.; GUAGGIO, J.A.; SILVA, J.R.; KAVATI, R.; MELETTI, L.M.M.; SÃO JOSÉ, A.R. Adubação do maracujá. In: RAIJ, B.Van.; CANTARELlA, H.; GUAGGIO, J.A.; FURLANI, A.M.C. Recomendações de calagem e adubação para o Estado de São Paulo. Campinas: Instituto Agronômico, 1996. p.148-149.

RAIJ, B.van; CANTARELLA, H.; QUAGGIO, J.A.; FURLANI, A.M.C. (Ed.) Recomendações de adubação e calagem para o Estado de São Paulo.2.ed. Campinas: Instituto Agronômico \& Fundação IAC, 1996. p.39. (Boletim Técnico, 100).

RAIJ, B.van.; ANDRADE, J.C.; CANTARELLA, H.; QUAGGIO, J.A. (Ed.) Análise química para avaliação da fertilidade do solo. Campinas: Instituto Agronômico, 2001. 285p.

RANGEL, L.E.P;; PEIXOTO, J.R.; JUNQUEIRA, N.T.V.; OLIVEIRA,A.T.O.; FORTALEZA, J.M. Desempenho agronômico do maracujazeiro-azedo cultivado sob três diferentes níveis de adubação potássica no Distrito Federal. In: CONGRESSO BRASILEIRO DE FRUTICULTURA, 17., 2002, Belém. Resumos... Belém: SBF,EMBRAPA Oriental,2002. CD-Rom.

RUGGIERO, C. Maracujá para exportação: aspectos técnicos. Brasília: EMBRAPA-SPI,1996.11-29.

SANTOS, J.B.P.; CAVALCANTE, L.F.; FEITOSA FILHO, J.C.; LIMA, E.M.; SANTOS, C.J.O.; SILVA, A.P.P.; CAVALCANTE, I.H.L.;ALVES, G.S. Desenvolvimento vegetativo do maracujazeiro-amarelo em função das relações nitrogênio:potássio e cálcio:magnésio aplicadas ao solo. Anais do Curso de Pós-Graduação em manejo de solo e água, Areia,v.23,p.1-11,2001.

SANZONOWICZ, C.; SILVA, R.P.; PEIXOTO, J.R.; JUNQUEIRA, N.T.V.; OLIVEIRA, J.A. Efeito da adubação potássica na produção do maracujazeiro-amarelo (Passiflora edulis Sims f. flavicarpa Deg.). In: CONGRESSO BRASILEIRO DE FRUTICULTURA, 16., 2000, Fortaleza. Resumos... Jaboticabal: SBF, 2000. CD-ROM.

SÃO JOSÉ, A.R. Adubação do maracujazeiro: práticas de cultivo e mercado: Vitória da Conquista: DFZ/UESB, 1994. 29p.

SCHÖNAU, A.P.G. The effects of fertilizing on the foliar nutrient concentration in Eucalyptus grandis. Fertilizer Research, Dordrecht, v.2,p.73-87,1981.

SILVA, M.A.G.; BOARETTO, A.E.; FERNANDES, H.G.;BOARETTO, R.;MELO, A.M.T.; SCIVITTARO, W.B. Características químicas de um Latossolo adubado com uréia e cloreto de potássio em ambiente protegido. Scientia Agricola, v.58, n.3, p.561-566,2001.

SILVA, N.M.; CARVALHO, L.H.; QUAGGIO, J.A. Ensaio de longa duração com calcário e cloreto de potássio na cultura do algodoeiro. Bragantia, Campinas, v.54,p.353-360,1995.

SILVA, S.R.; BARROS, N.F.; NOVAIS, R.F.; PEREIRA, P.R.G. Eficiência nutricional de potássio e crescimento de eucalipto influenciado pela compactação do solo. Revista Brasileira de Ciência do Solo, Viçosa, v.26,n.4,p.1001-1010,2002.

SOUSA, V.F.; FOLEGATTI, M.V.; FRIZZONE, J.A.; CORRÊA, R.A.L.; ELOI, W.M. Produtividade do maracujazeiro-amarelo sob diferentes níveis de irrigação e doses de potássio via fertirrigação. Pesquisa Agropecuária Brasileira, Brasília, v.38, n.4, p.497-504,2003.

TEIXEIRA, L.A.J.; NATALE, W.; RUGGIERO, C. Alterações em alguns atributos químicos do solo decorrentes da irrigação e adubação nitrogenada e potássica em bananeira após dois ciclos de cultivo. Revista Brasileira de Fruticultura, Jaboticabal, v.23,n.3, p.684689,2001. 